\title{
IN MEMORIAM: NICOLÁS CAPARRÓS SÁNCHEZ (1941-2021)
}

Intervienen: Alejandro Ávila Espada, Carlos Rodríguez Sutil, Lola Lorenzo López y Felipe Vallejo Jiménez, Emilio Irazábal, Begoña Olabarría ${ }^{1}$

\section{Ecos de historia grupal con Nicolás Caparrós Sánchez}

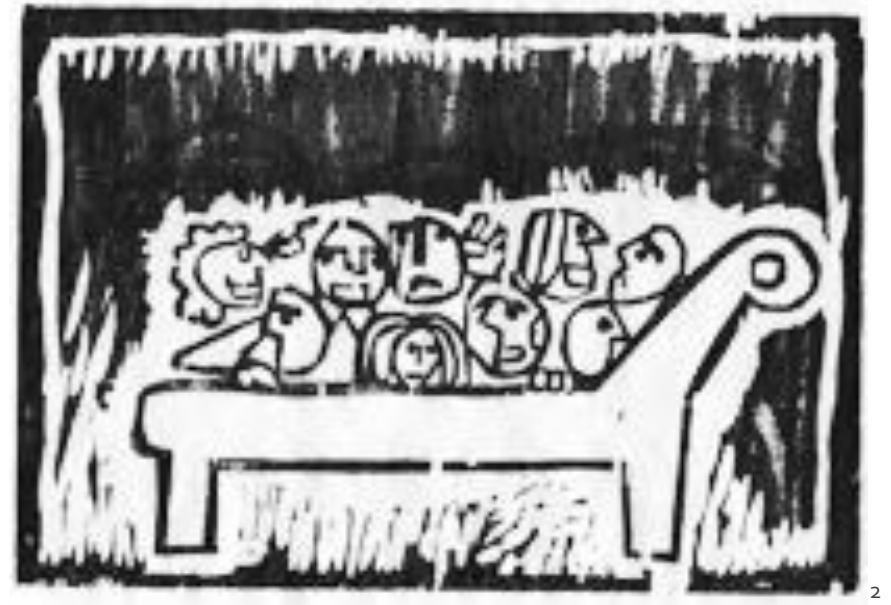

\section{Alejandro Ávila Espada}

Evocar la significación, personal y colectiva, de Nicolás Caparrós Sánchez (1941-2021) es trazar una compleja y rica historia grupal. Solo puedo referirme con intensidad al período entre 1974 y 1992, en gran medida compartido con diferentes niveles de intensidad, que incluyen lo institucional y lo privado hasta nuestro distanciamiento en 1998. Por ello lo relativo a la experiencia directa de su evolución en los últimos 22 años no será recogida aquí. Pero las etapas que serán mencionadas tienen una gran trascendencia propia y singular, por el significado de una época, y por las aportaciones realizadas por él en ellas.

Como uno de los coordinadores de los Cuadernos de Psicología Crítica que publicábamos en ciclostil en la Universidad Complutense un grupo de estudiantes hacia 1970-73, habíamos tenido contacto con sus escritos, exponentes del pensamiento dialéctico en Psicología, y que traían las ideas Sartreanas,

\footnotetext{
1 Ávila, A., Rodríguez, C., Lorenzo, L., Vallejo, F., Irazábal, E. y Olabarría, B. (2021). In Memoriam: Nicolás Caparrós (1941-2021). Clínica e Investigación Relacional, 15 (1): 298-314 [ISSN 1988-2939] [Recuperado de www.ceir.info ] DOI: 10.21110/19882939.2021.150118

2 Diseño gráfico elaborado por José Miguel Marinas Herreras en 1976, que refleja tanto la epistemología, el espíritu y la geografía humana de nuestro grupo en esa época.

CelR Vol. 15 (1) -Abril 2021 ISSN 1988-2939 - www.ceir.info

(c) Derechos reservados/Copyright de Clínica e investigación Relacional y los autores. Prohibida la reproducción total o parcial sin autorización expresa. Este material es para uso científico y profesional exclusivamente y puede contener información clínica sensible. Los editores no se responsabilizan de los contenidos de los autores. Dirigir las consultas sobre derechos y autorizaciones a ceir@psicoterapiarelacional.es
} 
de Georges Politzer y José Bleger a nuestro horizonte aún dominado por los planteamientos de una psicología de base Tomista. Conocí personalmente a Nicolás en 1974, cuando un pequeño grupo de psicólogos inquietos, que en esa época intentábamos descubrir y compartir lo que considerábamos una psicología alternativa nos acercamos a él, de la mano de Susana López Ornat. Recuerdo cuando Adolfo Hernández Gordillo (luego Decano del COP), entre otros, y yo mismo, le visitamos para incorporarnos a un grupo de estudio que el estaba formando tras regresar de su estancia y de las experiencias vividas en Argentina, donde había conocido de cerca los desarrollos de David Cooper ${ }^{3}$ en Villa $21^{4}$ (Buenos Aires) y había convivido con algunos de los discípulos más significativos de Enrique Pichon Rivière (Hernán Kesselman, Eduardo Pavlosky, Armando Bauleo, que después se trasladarían a Madrid) y también a grupalistas como Emilio Rodrigué y Norma Ferro, entre muchos otros. Su primo y destacado pensador Antonio Caparrós García-Moreno, pronto se incorporó también a este escenario en Madrid, ante las amenazas de persecución política y de muerte que se hicieron cotidianos en la vida en el Buenos Aires de esa época. Nicolás acababa de instalarse en el que sería su domicilio y despacho clínico, durante varios años en Príncipe de Vergara 204, Madrid, que fue también residencia inicial de algunos de los colegas que venían de Argentina, hasta que inició a finales de los años setenta otras experiencias de convivencia, que constituyeron su entorno de vida hasta avanzado 1982, momento en el que él definió el proyecto de familia que le ha acompañado el resto de su vida.

Antes de irse en 1972 dos temporadas a Argentina, Nicolás había estado trabajando en instituciones psiquiátricas: el Sanatorio Psiquiátrico Conde de Romanones de Alcohete (Guadalajara), en el que fue Residente, hasta que obtiene su plaza en el Hospital Psiquiátrico Santa Isabel de Leganés (Madrid), donde coincidirá con Juan Casco y Antonio Espino Granados, entre otros, y en donde vivió en primera persona y con responsabilidades clínicas los intentos iniciales de la reforma psiquiátrica en España.

Nicolás estaba imbuido del espíritu de la Antipsiquiatría y era promotor de la misma en España (una Antipsiquiatría principalmente de inspiración inglesa en esa época: Ronald Laing [desde 19565], David

\footnotetext{
${ }^{3}$ Cooper, un psiquiatra sudafricano afincado en Londres, fue el coordinador del congreso de la "Dialéctica de la Liberación", celebrado en Londres, en el Roundhouse de Chalk Farm desde el 15 al 30 de julio de 1967. Este congreso reunió a connotados intelectuales críticos de la época, como R. D. Laing, Paul Goodman, Allen Ginsberg, Herbert Marcuse y Stokely Carmichael. Con Laing y otros colaboradores, fundó la Asociación Filadelfia, basada en un marxismo existencialista, que abandono cuando consideró que se dejaba de lado la crítica política y social, que consideraba necesaria para lograr cambios profundos en el tratamiento de los pacientes psiquiátricos. Viajó entonces a Argentina, país que consideraba reunía entonces el germen revolucionario necesario para estos cambios.

4 Villa 21-24 - NHT Zavaleta es un asentamiento precario ubicado en la Comuna 4 de la Ciudad de Buenos Aires, República Argentina, abarcando sectores de los barrios de Barracas y Nueva Pompeya.

${ }^{5}$ Año en el que funda la comunidad "Kingsley Hall" promovida por la Philadelphia Association en Londres. Ronald D. Laing (1927-1989) es autor de numerosas y trascendentes obras, a partir de su clásico "The Divided Self: An Existential Study in Sanity and Madness" (1960), entre otras muchas. Su obra y pensamiento es difundida por el Instituto Laing en Suiza (http://www.lainginstitut.ch/)
}

@ Derechos reservados/Copyright de Clínica e investigación Relacional y los autores. Prohibida la reproducción total o parcial sin autorización expresa. Este material es para uso científico y profesional exclusivamente y puede contener información clínica sensible. Los editores no se responsabilizan de los contenidos de los autores. Dirigir las consultas sobre derechos y autorizaciones a ceir@psicoterapiarelacional.es 
Cooper [desde $1962^{6}$ ], Aaron Esterson7, Joseph Berke [desde 1965 ${ }^{8}$ ]) que fue lo que le llevó a Buenos Aires, incitado por Antonio Caparrós García-Moreno, para conectar con los nexos argentinos del grupo Plataforma, en el que participaría Armando Bauleo, principalmente, y también con disidentes de la Asociación Psicoanalítica Argentina (APA): Hernán Kesselman, Eduardo Pavlosvky, entre otros. Varios de ellos estaban en relación también con los movimientos europeos, ya incluidos el grupo italiano de Trieste [desde Basaglia, 19689' y en la constitución del grupo Plataforma ${ }^{10}(1969,1975)$.

Su interés por las propuestas de los antipsiquiatras, que había conocido indirectamente en sus estancias en Londres, y también su colaboración en la encuesta sobre la sexualidad ${ }^{11}$ realizada en la universidad a finales de los sesenta por Caba Catalán, en la que Nicolás colaboró, así como el trabajo psicoterapéutico realizado con la Psiquiatra Rita Enríquez de Salamanca y cuyas conclusiones quedan recogidas en un documento de $1970^{12}$, están presentes en su primera obra bien conocida "Crisis de la familia. La revolución del vivir" (Buenos Aires: Kargieman, 1973³; Madrid: Fundamentos, 1977). En 1970, con Rita Enríquez, afirma: "En el marco en que nos movemos (la práctica psicoterapéutica con estudiantes universitarios), las premisas que resultan más eficaces para abordar una psicoterapia consciente de sus propios límites han sido: 1) Los conflictos llamados personales tienen siempre un claro entronque social; 2) ... la psicoterapia esclarece únicamente las decisiones personales a tomar frente a conflictos sociales pero por sí sola no los soluciona..." (p. 305-306).

Cuando Nicolás regresó a Madrid, a principios de 1974 participó en un ciclo de conferencias ${ }^{14}$ que había organizado José Luis de la Mata, y en dos intervenciones, en las que expuso las ideas que están también recogidas en su contribución al volumen "Laing. Antipsiquiatría contracultura" (Madrid: Fundamentos, 1973) muestra al psicoanálisis como "víctima de su propia ambivalencia que le impide

\footnotetext{
${ }^{6}$ David Cooper (1931-1986) quien funda una comunidad en Villa 21, en Buenos Aires. Aportó destacadas obras como: "Razón y violencia" (con R. Laing, 1964); "Psiquiatría y antipsiquiatría" (1967); "Dialéctica de la liberación" (1968); "La muerte de la familia" (1971) y "El lenguaje de la locura" (1978).

${ }^{7}$ Aaron Esterson (1923-1999), co-funda con R. Laing la Associación Philadelphia, con quien publica una de sus obras más conocidas: "Cordura, locura y familia, 1964)

${ }^{8}$ Trabaja con Mary Barnes en 1965; Funda Arbours Association en 1970 y el Arbours Crisis Center (London, 19732010)

${ }^{9}$ Año en el que Franco Basaglia publica "La institución negada", punto de arranque de lo que culminaría en Italia con la Ley 180/1978, que supuso el cierre gradual de hospitales psiquiátricos, y estableció que los tratamientos psiquiátricos debían de ser voluntarios (considerando los obligatorios como excepciones).

10 Red europea de alternativa a la psiquiatría: colaboración entre trabajadores, expertos profesionales, defensores de la democracia. La primera reunión de Plataforma Internacional tuvo lugar en Roma en 1969 en la que también participarán Armando Bauleo, Marie Claire Booms, Hernán Kesselman, Emilio Rodrigué y Berthold Rorschild.

${ }^{11}$ Incluida como apéndice en la obra compilada por A. Bauleo "Vicisitudes de una relación" (Buenos Aires: Granica, 1973)

${ }^{12}$ Titulado "Psicoterapia y represión" y que fue incluido en la compilación citada de Bauleo (1973).

${ }^{13}$ Esta obra apareció primero en Buenos Aires, pues todavía no se daban las condiciones más adecuadas en España para su publicación.

${ }_{14}$ Realizado del 11 al 16 de Enero, en Madrid, y sus intervenciones fueron el 15-1 (El modelo actual de la situación antipsiquiátrica) y el 16-1 (Los diferentes modelos de la antipsiquiatría). En este ciclo intervino también Rafael Burgaleta, y el propio José Luis de la Mata
} 
llevar su práctica (liberadora de la represión) a sus últimas consecuencias" (lo que llamará Psicología de la Liberación ${ }^{15}$ ) en la que el contexto y la práctica grupal ofrece las mayores potencialidades. Nicolás se decanta entonces por lo que denomina una "psicología dinámica que parte de la vida cotidiana"16 $\mathrm{y}$ en la que reconocer y expresar "Qué es el hombre concreto, es la tarea de una psicología que hasta ahora se ha empeñado en contarnos cosas de él"17 es decir, entender lo singular humano como producto de su contexto concreto, un contexto social e interpersonal. Un conjunto de ideas que reunían los giros aportados por la contracultura europea y americana, el pensamiento crítico, social e interpersonal que era heredero de Herbert Marcuse, Erich Fromm, Wilhem Reich, Jean Paul Sartre, y que era consonante con los desarrollos de Enrique Pichon Rivière. El marco de las transformaciones sociales de los setenta, fueron el caldo de cultivo y contexto del desarrollo de las propuestas en las que Nicolás Caparrós jugó un papel de liderazgo conceptual y catalizador del desarrollo de grupos y personas que dejaron una huella muy significativa en las dos décadas siguientes, en las que se formaron varias generaciones de profesionales de la salud mental.

Entre 1974 y 1977 Nicolás coordinó y gestionó en Madrid un grupo de formación, al que asistimos los primeros miembros de lo que enseguida sería el Grupo Quipú de Psicoterapia (desde 1975), además de otros asistentes que constituyeron en 1977 un grupo independiente con Armando Bauleo ${ }^{18}$, y en el que participaron como docentes el propio Nicolás, Antonio Caparrós, Armando Bauleo, Emilio Rodrigué, Marta Berlín, Norma Ferro y Angel Fiasché entre otros. La formación versó sobre Psicopatología, Psicoterapia individual y de grupo, Psicodrama, Tratamiento de parejas y familias, e Intervención en las Psicosis; este programa se completó con experiencias intensivas de grupo (laboratorios) y psicodrama analítico, realizados con Armando Bauleo, Eduardo Pavlovsky, Hernán Kesselman, Norma Ferro y Emilio Rodrigué, además de Nicolás. He estimado las actividades formativas que realizamos en esa época en no menos de 700 horas efectivas. Desde 1978, se unieron a este efervescente escenario las actividades promovidas por Hernán Kesselman, que incluyeron seminarios con Fernando Ulloa, Mauricio Goldemberg, Joseph Berke y Salomon Resnik, entre otros destacados maestros.

La obra que recoge mejor ese clima grupal que se fue gestando y ampliando a lo largo de la década de los setenta, y la primera mitad de los ochenta fue "Psicología y Sociología del Grupo"19 donde se definen elementos para un marco donde "el hábitat 'normal' presente objetivo o fantástico del ser humano es el grupo (...) No existe el hombre solo..." (1976, p.9). Nos formamos en los referentes directos de esta obra, y en su desarrollo hacía las perspectivas interpersonales, socio-culturales, del

\footnotetext{
${ }^{15}$ A. y N. Caparros (1976). Psicología de la Liberación, Madrid: Fundamentos.

${ }^{16}$ A. y N. Caparros, 1976, op. cit. página 15.

${ }^{17}$ A. y N. Caparros, 1976, op. cit. página 256.

${ }^{18}$ Entre los que figuraban otros de los contribuidores a este In Memoriam, como Emilio Irazabal, Lola Lorenzo, Begoña Olabarría, además de Consuelo Escudero, Félix García-Villanova y muchos otros. El entonces llamado "Grupo de Bauleo" se inclinó más por la práctica en las instituciones, donde jugaron un papel muy trascendente durante décadas, incluyendo algunas de las figuras más relevantes de la reforma psiquiátrica y de la atención en Salud Mental en España

${ }^{19}$ A. Bauleo, A. Caparrós, N. Caparrós, S. Díaz, N. Labrucherie, S. López Ornat, S. Marrero, E. Pavlovsky: "Psicología y sociología del grupo" (Madrid: Fundamentos, 1976)
} 
grupo operativo pichoniano y de la psicoterapia del grupo $^{20}$, confrontadas con los retos de transformación de la sociedad y grupos humanos concretos en los que se aplica, y fuimos construyendo - y transmitiendo- una práctica que era esencialmente grupal ${ }^{21}$, para una liberación del hombre situado en su contexto e implicado en la transformación del mismo y en la superación de sus contradicciones.

Otro documento esencial para entender el punto de vista personal de Nicolás, y lo que compartíamos con él, la impronta que nos transmitía, es la editorial del número inaugural de la revista "Clínica y análisis grupal" la revista que fundé en 1976, con el apoyo entusiasta de Nicolás Caparrós, Susana López Ornat, Hernán Kesselmann y mis compañeros miembros del Grupo Quipú de Psicoterapia 22 , y otros colaboradores esenciales en el proyecto inicial como Paloma de Pablos Rodríguez y José Miguel Marinas Herreras ${ }^{23}$. Sus dos primeros años, con 13 números publicados incluyen frecuentes trabajos de Armando Bauleo, Joseph Berke, Antonio y Nicolás Caparrós, Aaron Esterson, Eduardo Pavlovsky, Luis Frydlevsky, Manuel González de Chavez, Hernán Kesselman, Susana López Ornat, Eduardo Paolini, Guillermo Rendueles Olmedo, Fernando Ulloa, Luis Weinstein, entre muchos otros. Nuestra primera editorial, fiel reflejo del pensamiento de Nicolás Caparros, y del nuestro con él, proclamaba: "...pensar en el hombre como personificación de los social ... nos lleva a plantear una publicación en la que teorías dispares, técnicas distintas, se contextúen en una lectura ideológica común. En este caso la que representa todo aquello que es funcional al cambio, al aprendizaje permanente, a la crítica continua, a la sustitución de lo establecido por lo provisional, al enfoque de pensamiento basado en categorías relativas... una ideología definida por las coordenadas del materialismo histórico" (Noviembre de 1976) 24 "Trasladar el acento a ... una psicología grupal como base científica del ser humano" (Enero de 1977) $)^{25}$

\footnotetext{
${ }^{20}$ En oposición a los enfoques psicoanalíticos convencionales del grupo, que en esa época reproducían las pautas del psicoanálisis clásico situado en un escenario grupal.

${ }^{21}$ El capítulo de esa obra que mejor plasma el espíritu, propósito y método grupal y clínico que seguíamos es "Teoría y práctica de los grupos operativos" de Nicolás Caparrós y Susana López Ornat. Otras obras en las que se muestra el pensamiento grupal de Nicolás Caparrós son: Psicología dinámica

grupal. Madrid: Fundamentos, 1980; con Juan Campos, Hernán Kesselman y otros); Los Ataques al vínculo grupal (Comp. Oscar Álvarez, 1994); la compilación de los trabajos grupales que reuní en los 2 volúmenes de "Manual de Psicoterapia de Grupo Analítico-Vincular" (A. Avila (comp) Quipú ed., 1993); el grupo creó al hombre (Con I. Sanfeliú y otros, B. Nueva, 2004)

${ }^{22}$ El Grupo Quipú de Psicoterapia fue un proyecto grupal que realizó trascendentes aportaciones en sus primeros veintitres años de existencia y luego derivo en otras formaciones institucionales. Sus miembros fundadores, además de Nicolás Caparrós Sánchez, Susana López Ornat y yo mismo, incluyen a Antonio García de la Hoz, Alicia Martínez Muñoz, Juan José Rueda Jaimes, Isabel Bombin Bombin, Carlos Cabello Suñen, Pilar Alonso Ortíz, Paloma Fernández Torres, Concepción Álvarez Moreno, Paloma de Pablos, Luis Conde. Algunos de ellos dejaron el grupo en los años siguientes, otras personas estuvieron cerca del grupo o se incorporaron a él en momentos posteriores. He publicado varias reseñas históricas sobre el grupo: "Algunas notas sobre la historia y contenidos del 'Grupo Quipú de Psicoterapia'" (Anthropos, 29); "Algo de historia grupal, $1^{\mathrm{a}}$ entrega" (Clínica y Análisis Grupal n68, 1995) con ocasión del XX aniversario;

${ }^{23}$ Quien además hizo el proyecto gráfico y numerosas ilustraciones incluidas en los primeros años.

${ }^{24}$ Fragmentos de la Editorial del número 1 de Clínica y Análisis Grupal

$25 \mathrm{lbid}$. Anterior, Editorial del número 2.
} 
Llevé personalmente la dirección de esa revista hasta su número $33(1984)^{26}$, cuando estaba en su octavo año, y a partir del n 34 asumió la dirección Nicolás Caparrós con un comité de redacción coordinado por Isabel Sanfeliú y José Antonio Reguilón. En el editorial que inicia la nueva etapa desde 1984 se subrayaba la necesidad de dotar a los agentes de práctica grupal de conocimientos psicoanalíticos y psicopatológicos, lo que es indudable, pero que viene ejemplificado por una presencia significativamente mayor de los temas psicoanalíticos convencionales frente a los grupales y comunitarios en los años siguientes de la revista, que finalmente dejó de publicarse en 2010 tras 105 números. En esa década y media entre 1984 y 1998 algunos fuimos trazando otros caminos junto al principal de la práctica clínica grupal: el proyecto de una unidad de tratamiento de personas con psicosis (Carlos Cabello), el despliegue de docencia e investigación en la universidad y la implicación en el desarrollo profesional y formativo de la Psicoterapia (Carlos Rodríguez Sutil, Antonio García de la Hoz y yo mismo) o de la salud mental comunitaria (Carlos Rodríguez Sutil).

Nicolás venía trabajando desde finales de los setenta en elaboraciones de psicopatología psicodinámica, que aparte de varios artículos muy relevantes, se plasmó primero en su obra " $L a$ construcción de la personalidad. Las psicopatías" (1981) cuya parte final fue escrita en un viaje compartido por Escandinavia en 1980. Esa obra fue un manual de cabecera imprescindible, hasta que publicó sus dos volúmenes de "Psicopatología Analítico Vincular" (1992) que lo ampliaron significativamente.

A partir de las bases dialécticas descritas, y desde su filiación inicialmente freudo-marxista crítica (especialmente crítica con el marxismo en sí), Nicolás evolucionará, y fijará de nuevo ${ }^{27}$ su interés fundamental en la figura de Sigmund Freud y el Psicoanálisis, quedando en un lugar menos principal el pensamiento grupal (que sin embargo seguirá trabajando en su práctica psicoterapéutica) y la psicopatología vincular (en la que seguirá trabajando en su desarrollo teórico hasta 1992 y que se plasma en diferentes obras ${ }^{28}$ ). Hacia 1985 realiza con Antonio García de la Hoz y la ayuda de Rafael Aburto, una nueva traducción desde el alemán de la pionera obra de J. Breuer y S. Freud (1895), los "Estudios de la Histeria" (traducción que no llegó a ser publicada), que vendrá seguida por la realización de su tesis doctoral (1988), un cuidado ensayo sobre la Correspondencia de Freud, que continuará con la re-traducción y compilación completa de la correspondencia de Freud, una obra enciclopédica, que aparecerá entre 1995 y 2002 en 5 volúmenes, y que tendrá como corolario una traducción comentada y comparada de "Die Traumdeutung " que aparece publicada en el año 2000 como "Psicoanálisis de los sueños. El sueño del Psicoanálisis".

Así pues, germinado en su trayectoria e inquietudes de siempre, pero más explícito a partir de principios de los ochenta, Nicolás retorna al psicoanálisis, elaborando su reinterpretación y lectura

\footnotetext{
${ }^{26}$ Segui colaborando con regularidad en Clínica y Análisis Grupal hasta 1997, con contribuciones propias hasta el número 68.

${ }^{27}$ Siempre había tenido ese interés, pero se dedicó intensivamente a él desde 1985.

28 "La anorexia. Una locura del cuerpo" (con I. Sanfeliú, 1997); "Ser psicótico. Las Psicosis" (2004); " El proceso psicosomático. El ser humano en el paradigma de la complejidad" (2008).
} 
propia $^{29}$. Un viaje que a partir del año 1992 puede denominarse "viaje a la complejidad"30 que se plasma primero en su obra "Tiempo, temporalidad y psicoanálisis" (1994), donde sus inquietudes epistemológico-conceptuales y psicoanalíticas ya ocupan su centro de atención, la ya mencionada obra con la correspondencia de Freud, y una variedad de trabajos en que se unen sus inquietudes psicoanalíticas, epistemológicas y psicopatológicas que se recogen en sus publicaciones: "Del narcisismo a la subjetividad: el vínculo" (1998); "Más allá de la envidia" (2000); "Orígenes del Psiquismo. Sujeto y Vínculo" (2004) y principalmente "Viaje a la Complejidad" (Con Rafael Cruz Roche, 2012, 2013, en 4 volúmenes). Algunos de los que comenzamos con él nuestra trayectoria, marcamos una evolución diferente, que manteniendo las raíces de la tradición interpersonal, social, grupal y cultural del psicoanálisis ${ }^{31}$, evolucionamos hacia una perspectiva relacional en psicoanálisis y psicoterapia.

La esencia del grupo es su proceso y capacidad de cambio. El grupo emerge, crea, se transforma y/o muere. Las personas somos más limitadas, y cada una tenemos nuestro contexto de posibilidad, nuestros horizontes y límites. Vivir los momentos grupales, posibles por la fuerza transformadora del grupo y de sus integrantes fue un gran privilegio compartido. Nicolás Caparrós fue un maestro y catalizador de muchos registros en nuestra etapa formativa, nunca acabada: psicosocial, psicopatológico, psicodinámico, comunitario. En un momento histórico en el que el pensamiento crítico era un bien escaso, Nicolás Caparrós, como también lo fue Carlos Castilla del Pino o lo sigue siendo Jorge L. Tizón, representaba un luminoso faro al margen de la psiquiatría oficial, de valía incuestionable, que abrió muchos horizontes, y que destacó en un panorama al que se añadieron los muchos profesionales quienes promovieron la reforma psiquiátrica en España, la Salud Mental Comunitaria, y el avance de la psicoterapia en una pluralidad de ámbitos, desde la psicodinámica, lo grupal, lo sistémico y lo humanista, un proceso que continua vivo. Gracias por lo vivido y lo transmitido en aquella década (hasta 1985) y por lo compartido hasta avanzados los noventa. El duelo viene pues de muy atrás, pero ahora se muestra plenamente. La inevitable despedida, con Gardel ${ }^{32}$ :

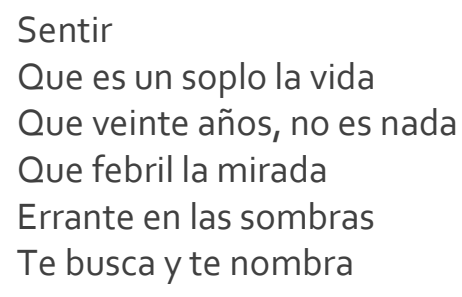

${ }^{29}$ Un relato de primera mano sobre el periodo a partir de 1981 esta publicado como relato biográfico y documental en: Sanfeliu, I. (2013). Autores de referencia: Nicolás Caparrós, una vida apasionada. Teoría y práctica grupoanalítica, 3(2):293-314; Cuando en 1998 deja el Grupo Quipú de Psicoterapia y funda su nuevo proyecto: Imago, lo define como "Clínica Psicoanalítica e Instituto de Investigaciones Metapsicológicas".

$3^{\circ}$ Véase sobre este tema la entrevista videograbada que le hace en 2012 Vicente Brox en el COPM (https://www.revistaclinicacontemporanea.org/art/20120306135551656000\#contenido). Véase también la entrevista que le realiza también Vicente Brox y publicada en Clínica y Salud, vol. 18, núm. 1, 2007, pp. 119-126. ${ }^{31}$ Véanse entre otras obras: A. Ávila (comp.) La tradición interpersonal (Ágora Relacional: 2013); C. Rodríguez Sutil: Psicopatología Psicoanalítica Relacional (Ágora Relacional, 2014); A. Ávila (comp). Relational Horizons (IPBooks, 2018).

${ }^{32}$ Estrofas finales de "Volver" (Alfredo Lepera / Carlos Gardel, 1934) 


\author{
Vivir \\ Con el alma aferrada \\ A un dulce recuerdo \\ Que lloro, otra vez
}

Alejandro Ávila, 30 Marzo 2021

\title{
RECUERDOS DE NICOLÁS CAPARRÓS
}

\section{Carlos Rodríguez Sutil}

Conocí a Nicolás en el año 79 del pasado siglo. Siendo paciente suyo aprendí la mayor parte de lo que hoy sé sobre psicoterapia, en un sentido práctico y afortunadamente heterodoxo. Para que el lector se haga una idea de su estilo peculiar, de entrada, atendía sentado en una mecedora con un ligero vaivén, a veces no tan ligero. Por ahí entendí que, por una parte, es sumamente importante que el terapeuta esté cómodo y, por otra, que el paciente no tiene por qué sentir extrañeza por ciertos detalles. Si es su primera terapia, no tiene por qué pensar que la posición del terapeuta es extraña supongo que con ciertos límites - y en el caso de que haya realizado antes otras terapias, no sabe cómo es la terapia con este terapeuta en concreto. Otra cosa fundamental que aprendí es a hacer preguntas y observaciones al paciente, como decía Nicolás, "estilo portera". Quiere esto decir, que nuestro excelso conocimiento de las teorías, psicoanalíticas o no, nunca debe impedirnos ver lo que tenemos delante de las narices y cuya devolución permite al paciente un mejor conocimiento de su realidad. Dios nos libre de un terapeuta listo, decía H.S. Sullivan. La acumulación de observaciones más o menos evidentes es la que permite un conocimiento cabal de las personas, y no las inferencias de alto nivel muy impregnadas de teoría, quizá esta es una definición sencilla de lo que es un análisis fenomenológico. El proceso de enfermar es algo que se produce en un contexto familiar y social, a lo que se une el concepto de "chivo expiatorio". Por eso el grupo es también un lugar ideal, "una vía regia" - era una expresión que usaba a menudo - para observar y trabajar los problemas en el vínculo, en su propio surgimiento en las relaciones entre los integrantes.

En un laboratorio de fin de semana - viernes tarde, sábado y domingo - nos colocó a los participantes en dos filas, uno enfrente del otro, nada más llegar, en silencio. Gente que no nos conocíamos de nada. Después de unos minutos pidió a cada uno que dijera en voz alta cosas que "veía" en el otro. Eso no nos lo habían enseñado en la facultad. El acierto de los comentarios parecía cosa de magia. Los ejercicios removían y permitían resolver, ansiedades muy enraizadas en el fondo de nuestra experiencia. Los caballeros de la tabla redonda, el nacimiento, el jardín de infancia, el guateque, la barca, etc. Luego se analizaba la experiencia de cada uno en grupos pequeños, en el grupo conjunto y en la terapia individual de cada uno. El domingo por la noche terminábamos en una cena en algún buen restaurante donde intentábamos disolver poco a poco el pegamento que nos unía después de tantas horas de experiencia juntos. 
Yo había tenido la gran suerte de coincidir con Alejandro Ávila, profesor de Psicodiagnóstico en quinto, en la Complutense, que bastante nos pudo contar "fuera de programa". Gracias a él se me abrió un mundo y empecé mi formación en Quipú. También gracias a ellos y a otros grandes maestros que venían, o habían venido, de Argentina, como Emilio Rodrigué, con el que hicimos "el grupo de los grupos" junto con Nicolás (calculo que en año 81), Hernán Kesselman, Antonio Caparrós, Armando Bauleo, muchos más, en la estela de Enrique Pichón Rivière y José Bleger. También aprendí la psicopatología dinámica vincular, fundamento y estructura de mi desarrollo profesional, con mi lectura del libro La construcción de la Personalidad: Las Psicopatías (1981), y de numerosos artículos de Clínica y Análisis Grupal.

Eran los años de movida, de Barrio Malasaña, Café La Mandrágora, cines Alphaville, Pepi, Luci, Bom... Cuando salíamos de clase "redondeábamos" nuestra formación ante una cerveza en el Criscar, de la calle Ayala, donde Nicolás a menudo nos acompañaba. La suya era una de las conversaciones más amenas que he conocido, plagada de anécdotas sabrosas, propias y ajenas. Recuerdo con cariño a compañeros de curso: Jaime Nosti, Gustavo Cubero, Benita Ramírez, Paloma Ramos, Mercedes Rodríguez, Ángela Roales, Carmen Blanca, Carlos Figueroa, tristemente fallecido durante la formación, y otros y profesores como Susana López Ornat, Eduardo Paolini, Juan José Rueda, Antonio García de la Hoz, que algunas veces también se tomaban algo con nosotros.

Una tarde, en el descanso entre clase y clase, llegó una compañera de otro curso, muy alterada por la noticia del intento del Golpe de Estado (23-2-81). A partir de ahí se interrumpieron nuestras actividades y nos dedicamos a seguir con ansiedad los acontecimientos. Terminamos un grupo en casa de Nicolás, viendo la televisión hasta que el "emérito" se asomó a la pantalla para restablecer el orden constitucional, no con mucha prisa. Fruto de mi juventud e inmadurez - ya solo me queda de lo segundo - yo le había comentado a Nicolás que el sistema democrático que habían impuesto me parecía un engaño, y que hicieran lo que quisieran. Él me respondió que, a pesar de sus defectos, el cambio democrático era algo muy positivo. Que pensara en algo tan simple como que pocos años antes no se podía hacer terapia de grupo en un centro privado: "que los árboles no te impidan ver el bosque".

Los cursos terminaron y la relación se fue diluyendo, con altibajos, en los años siguientes. Luego hubo disensiones que prefiero no recordar, cuyo resultado fue que nuestro contacto se interrumpió. Coincidimos en algunos actos públicos y el trato se mantuvo cortés pero distante. Siento no haber intentado una nueva aproximación con él. Eso ya no tiene remedio. Me quedo con el recuerdo de un gran maestro y de una época en muchos sentidos gloriosa.

Carlos Rodríguez Sutil, 7 de Abril 2021 expresa. Este material es para uso científico y profesional exclusivamente y puede contener información clínica sensible. Los editores no se responsabilizan de los contenidos de los autores. Dirigir las consultas sobre derechos y autorizaciones a ceir@psicoterapiarelacional.es 


\section{RECORDANDO A NICOLÁS CAPARROS}

\section{Lola Lorenzo López y Felipe Vallejo Jiménez}

Un buen amigo, Emilio Irazábal, nos escribió para decirnos que había fallecido Nicolás Caparrós. Compartió con nosotros su escrito para o sobre Nicolás, que publicaría en Área 3. Fue al día siguiente de su muerte, el 22 de marzo.

Esta noticia nos conmovió, más de lo que podíamos imaginar. Creo que nos convocó muchos recuerdos, añoranzas, pérdidas e ilusiones.

¡Fue importante conocerle, en una época muy especial, donde comenzábamos tantas cosas! .

Con él empezamos un momento muy significativo de nuestras vidas, tanto profesional como personal.

Los orígenes, dicen que casi siempre son míticos, y que los recuerdos quedan construidos por múltiples vivencias y vínculos que se entrecruzan, será eso el responsable de la inquietud, nostalgia y tristeza que nos ha acompañado durante unos días.

Conocimos a Nicolás, allá por el año 74075 , meses antes de la muerte del dictador. Hechos coincidentes con nuestros primeros pasos en el campo de la psicoterapia grupal, el psicoanálisis, y la militancia política y social. Estar contra la dictadura era entrar en campos de conocimientos prohibidos, invisibilizados. Hoy, más que nunca, no podemos olvidar ese momento.

En la Facultad de Psicología de Somosaguas, Lola conoció a Alejandro Ávila, Antonio García de la Hoz y a otros compañeros. Fueron nuestros hermanos mayores, ellos nos presentaron a Nicolás Caparros. Estaban estudiando con él, y nos invitaron a unirnos a los cursos que hacía Nicolás. El lugar donde se impartía el curso era muy simpático; lo llamábamos "la guardería" (era un jardín de infancia).

En una sala de esta guardería, quienes acudimos al curso, conocimos a Armando Bauleo que, junto con Nicolás, nos dieron un seminario, (Bauleo todavía no se había exiliado).

Estábamos un grupo de compañeros de la facultad, expectantes. Tenemos vagos recuerdos de ese momento, pero lo que nunca olvidamos fueron las preguntas que Bauleo nos hizo, a unos psicólogos que todavía no habían terminado la Facultad. Empezó a enumerar una serie de autores, preguntándonos si los habíamos leído. Miradas, desconcierto, mala conciencia por ignorantes... Estuvo provocador, muy propio de él. Cuando salimos de la clase más de uno nos fuimos a comprar la Ideología Alemana de Marx, y La familia de Engels; curioso resultado para un seminario de psicoterapia. Y más todavía en una época en que comprar esos libros era toda una hazaña; (menos mal que estaba Fuentetaja). 
Y así empezamos a estudiar y a tratar de entender una concepción psicosocial del sujeto, una visión de lo colectivo, de la producción social de la subjetividad. Palabras, conceptos que hoy podemos nombrar de esta manera, pero que en aquel momento

eran estímulos, sugerencias, apoyaturas para el trabajo de psicólogo, y para el aprendizaje.

Habíamos encontrado poder unir la militancia política con el saber de un campo novedoso, entre ellos los grupos y el grupo operativo. Nicolas nos presentó a Pichon Rivière, a Bauleo, a Bleger, Lapassade, Lourau, Freud etc. Y con ellos seguimos

Nicolás fascinaba, como no podía ser de otra manera, por su saber, por la generosidad en compartir sus conocimientos, por intentar entender y empatizar con un grupo de psicólogos que apenas sabíamos que significaba este mundo profesional... y por darnos la oportunidad de conocer, de "abrirnos la cabeza", cuestionarnos.

No recordamos sentirnos criticados, censurados, tenemos, eso si, un cierto recuerdo de libertad para poder pensar...a pesar claro está, de las exigencias, valoraciones, de ese superyó maldito. Lo pasábamos bien, detrás de muchos encuentros había una fiesta...

Nos dio a conocer los movimientos de la antipsiquiatría a Basaglia, a Laing etc. Estaba al margen de las instituciones oficiales, no lo querían mucho, era demasiado izquierdista, demasiado psicoanalista y demasiado social.

Nicolás acompaño en estos primeros años (1976) a algunos de los psicoanalistas y discípulos de Pichon Rivière que tuvieron que exiliarse, Bauleo, Kesselman, Antonio Caparrós, Paulowky, A. Ingala etc. En Quipu, nos encontrábamos todos en distintos seminarios, talleres etc.

En uno de estos encuentros recalamos un grupo de profesionales de Sevilla. Era tal la importancia y resonancia que tuvo este movimiento en torno a Quipu, que desde Sevilla, en 1976, viajamos una pequeña delegación a Madrid, coincidiendo con un encuentro "maratón" para tratar la posibilidad de organización de una formación grupal en Sevilla durante tres años. Nicolás vino a Sevilla, al principio con Bauleo y Kesselman, y en el último ciclo, él solo. Fue una experiencia formativa importante en psicoterapia, análisis institucional, psicodrama, y en grupo operativo.

Como recuerda Emilio Iriazabal, Nicolás empujó a aquel entrañable encuentro de los grupos de formación de Madrid y Sevilla, con partido de futbol incluido, jugado en el campo del Colegio Aljarafe, (cuyo resultado Emilio Iriazabal insiste en tergiversar). Y posterior paella. Tampoco por estos lares recordamos el peso que tuvo la parte dedicada a lo "científico". Pero fue entrañable.

Posteriormente cada uno de nosotros fuimos buscando distintos caminos. . Algunos continuamos la formación con Bauleo. 
Creemos que Nicolás hizo mucho por la reforma psiquiátrica. Tuvo una buena parte en la formación de profesionales que teníamos que construir un campo nuevo: la salud mental, y que participábamos activamente en dicha reforma.

Gracias por los buenos ratos y por esa fabulosa revista Clínica y Análisis Grupal que fue pionera en el campo de la psicoterapia, del psicoanálisis, de la psicología social

analítica, del grupo operativo, del materialismo dialectico... En estos días hemos vuelto a revisar esta revista, y no deja de sorprendernos la calidad de los artículos, la variedad y el compromiso ético.

Durante muchos años dejamos de vernos, encuentros en los que, a algunos, nos reiteraba la necesidad de escribir pero No dejamos de conocer sus publicaciones. Siempre nos ha sorprendido su capacidad intelectual, sus desarrollos teóricos, su afán por escribir. Ha trabajado durante muchos años desarrollando lo que es su Modelo analítico vincular.

No podemos dejar de pensar en la historia de muchos de nosotros, los que comenzamos con él, y que hemos ido tomando caminos distintos, creando asociaciones, revistas, escuelas; transitando por momentos diversos, pero casi todos compartimos momentos que, seguramente "hoy recordándote", nos harían sonreír, y nos produciría ternura mirar a ese grupo de jóvenes con muchas ganas de aprender y disfrutar de una profesión que descubrimos en aquellos momentos, y que, en la parte que a Nicolás Caparros correspondía, poco tenía que ver con la oficial.

Queremos terminar este recuerdo y homenaje tomando unas notas de la editorial del primer número de Clínica y Análisis Grupal: ..."una publicación en la que teorías dispares, técnicas distintas, se contextúen en una ideología común. En este caso, la que representa todo aquello que es funcional al cambio, al aprendizaje permanente, a la critica continua, a la sustitución de lo establecido por lo provisional, al enfoque de pensamientos basado en categorías relativas, etc. Es, a fin de cuentas, una ideología definida en las coordenadas del materialismo histórico". Madrid noviembre 1976

Gracias Nicolás.

Sevilla 2-4-2021

Lola Lorenzo López. Miembro de APOP

Felipe Vallejo Jiménez. Miembro de APOP.

@ () Derechos reservados/Copyright de Clínica e investigación Relacional y los autores. Prohibida la reproducción total o parcial sin autorización expresa. Este material es para uso científico y profesional exclusivamente y puede contener información clínica sensible. Los editores no se responsabilizan de los contenidos de los autores. Dirigir las consultas sobre derechos y autorizaciones a ceir@psicoterapiarelacional.es 


\section{NICOLÁS CAPARROS. PARA ÉL O SOBRE ÉL}

\section{Emilio Irazábal}

Hace unas horas recibo un wasap de Antonio Tari diciendo que ha fallecido. Reacciono y escribo a Federico Suarez diciendo que algo voy a escribir para la web

El momento en que recibo el mensaje era bastante inadecuado para encajar la noticia. Pero imposible quitarlo de la cabeza. Y así llevo horas. Deseando llegar a casa para sentarme a escribir sobre él.

Agradecimiento para empezar. Agradecimiento para finalizar. Ese es el titular. Pero voy a explicar algo de ese agradecimiento.

Creo que el agradecimiento no es sólo mío. Pienso que varias generaciones de trabajadores de la salud mental estamos agradecidos hacia él por habernos puesto en el camino de entender nuestro oficio.

Hace muchos años que no he coincidido con él. La última vez fue una casualidad, aunque a juzgar por el sitio no era tan casual. Le encontré, hará unos diez o doce años, en el restaurante La Ancha, una de sus 'casas'. Estaba él cenando con Antonio Garcia de la Hoz. Encuentro breve, pero nos dio tiempo para recordar momentos especiales.

A Nicolás le conocí en 1973. Un grupo de estudiantes izquierdistas de Filosofía y Letras (sección de psicología) de la Complutense, decidimos 'tomar' la Asociación Cultural de esa Facultad (edificios recién estrenados en Somosaguas, donde continua la actual Facultad de Psicologia) y una de nuestras primeras acciones fue la realización de un Simposium sobre la Psicologia en España. Invitamos a Nicolás a dar la conferencia inaugural. Versó sobre La Antipsiquiatria. Era uno de sus temas, aparte de ser uno de sus principales portavoces en nuestro país.

Un año después, en otoño de 1974, creo que empecé a formarme con él. Con él y con su equipo que al año siguiente pasaron a constituirse como Grupo Quipú de Psicoterapia. Grupo vanguardia para la psicología de esa época. Sin paliativos.

Nicolás era una persona 'sesuda', su capacidad intelectual y cultural era significativa, le encantaba pensar, asociar libremente, pensar en voz alta, conversar, escuchar... Muy socrático. Me abrió al mundo de la psicología (a pesar de estar en cuarto de carrera, no sabía lo que era la psicología). Gracias a él (y a su equipo) conocí el psicodrama, el psicoanálisis, los cimientos de la psicoterapia, la psicología grupal... Paradojas de la vida, este viaje iniciático a la psicología lo realizamos en una escuela infantil de la calle Alfonso XIII de Madrid. Huemul era su nombre.

Y por si no fuera bastante lo que me enseñaba, asistía alguna vez como observador a un grupo de psicoterapia que él coordinaba. Agradecimiento. Mucho. 
Nicolás era, además, una persona hospitalaria y generosa. Gracias a él pudimos conocer a profesionales de alta talla internacional como Antonio Caparrós, Georges Lapassade, Eduardo Paulovsky, Hernán Kesselman, Armando Bauleo, y muchos otros.

Después de los dos años de aquel famoso curso que se llamaba "Seminario Crítico de Psicoterapia" (1974-1976), continué mi formación con Armando Bauleo,... hasta el final.

Dos años iniciáticos fantásticos. Y, además, como telón de fondo, las movilizaciones sociales y la euforia por la muerte de Franco

Ya he dicho que Nicolás era persona sesuda, hospitalaria y generosa. Pues además de todo eso, le gustaba divertirse. Y que te divirtieras con él.

Después de una de esas sesiones maratonianas de fin de semana que se llamaban "Laboratorios Sociales", organizó una fiesta en su casa. Algunos queríamos seguir más de fiesta y ya era tarde para el transporte a algún otro sitio. Me ofreció su coche recién comprado, un flamante Simca 1200 de color verde, que nos permitió a algunos seguir la fiesta en otro lugar. Estupefacto y derretido me dejo ese gesto tan afectuoso. Pero es que creo que era muy generoso.

Por esa época, Nicolás viajaba a formar a profesionales a Sevilla. Y no se le ocurrió mejor idea que organizar un 'Encuentro' entre sus alumnos madrileños y sus alumnos sevillanos. No recuerdo la parte intelectual de ese encuentro (incluso dudo de que la hubiera), pero lo que si recuerdo es el partido de futbol entre sevillanos y madrileños (a Nicolás también le gustaba el futbol). Todavía hoy, cuando me encuentro con Felipe Vallejo (psicólogo sevillano y miembro de APOP), discrepamos sobre el resultado de ese partido. Felipe no lo sabe, pero en el fondo me da igual quien ganara. Para mí, ese viaje fue una victoria.

Bueno, en realidad, fueron una victoria esos dos años con Nicolás. Una victoria sobre mi analfabetismo psicológico. Agradecimiento.

Hace mucho de esto que cuento, pero fue tan importante...

Muchos recuerdos y muy bien instalados en mi interior.

Gracias Nicolás

Anochecer del 22 de marzo de 2021

Emilio Irazábal

P.D.: hace unos años, la revista Antropos dedicó uno de sus números especiales a Nicolás (para los que no tuvieron la suerte de conocerle). 


\section{UN MAESTRO QUE QUEDA ENTRE NOSOTROS:}

\section{ANTE EL FALLECIMIENTO DE NICOLÁS CAPARRÓS.}

\section{Begoña Olabarría 33}

Hoy, cuando aún me parece que puedo escuchar su palabra, ver su expresión, fijarme en su mirada -tan especial-. Hoy, cuando aún no han pasado más que pocos días de su fallecimiento -el día 21 de este mes de marzo-, puedo ver que tuve suerte: la tuve muy joven, en 1976, psicóloga recién licenciada, cuando buscaba en aquel erial de la formación en clínica y en Psicoterapia que era la España de mitad de los setenta -con sus islas de excepción-, dónde y con quién iniciar mi formación. Encontré un maestro. Cierto, seguro, riguroso, abierto, generoso en la administración y transmisión de su saber, favorecedor de la autonomización, tan alejado del capillismo como del caudillismo.

Nicolás Caparrós había vuelto hacía un par de años de Buenos Aires y había creado en Madrid Quipú, un singular Centro de Psicoterapia Psicoanalítica y Grupal, con un pequeño grupo de jóvenes psicólogos a los que había formado. Y abrió un camino de maestro: tratamientos psicoterapéuticos (individuales y grupales), formación en Psicoanálisis y en el Modelo Teórico-técnico del Grupo Operativo, Investigación y "laboratorios sociales"..., una revista (Clínica y Análisis Grupal), y abría una línea de publicaciones y libros que iban dando cuenta de sus aportaciones teórico-técnicas y su investigación psicoanalítica y psicoterapéutica, mientras también apoyaba desarrollos y publicaciones de terceros. Nada había como aquello que él empezó. Tuve una enorme suerte.

Más tarde desarrolló y mantuvo en Imago su equipo y colaboradores un camino sin paradas, sostenido, riguroso, sin sesgos capillistas, sin generar dependencias, abierto, profundo.

Psiquiatra, había dado sus primeros pasos en el Hospital Psiquiátrico de Alcohete, un manicomio marcado por la miseria y el asistencialismo, que Nicolás enfrentó con múltiples acciones de línea antipsiquiátrica. Obtiene plaza en el PANAP -Patronato nacional de asistencia psiquiátrica- y entra en el Hospital Psiquiátrico Nacional de Leganés como Médico ayudante, donde pasa a ser Jefe clínico y finalmente Jefe de servicio. Las condiciones aquí eran mejores que en Alcohete y se abrían camino por entonces terapias de grupo de corte variopinto y técnicas inciertas. Así que sus estancias en Londres abundan y desde el convencimiento de que era preciso "saber-hacer" en clínica ("Me adentré en el psicoanálisis a través del enfermo"), hace su formación analítica al tiempo que se aproxima a la rigurosa labor que se desarrollaba con psicóticos en Kingsley Hall, una de las experiencias más radicales en el tratamiento de estos pacientes. Como Assistant del Hospital Maudsley, coincidirá en 1968 con J. Berke, R. D. Laing, D. Cooper, A. Esterson y M. Schatzman. Con ese bagaje formaliza en el pabellón de hombres de Leganés las terapias de grupo manteniendo su preocupación e interés por la ideología y la problemática social en el Psicoanálisis, y así en 1969 en Roma, participa en la fundación de Plataforma

33 Expresidenta de FEAP 
Internacional como un modo de articulación de respuesta a la Internacional de Psicoanálisis, sobre todo en lo concerniente a la orillada problemática social, junto a Armando Bauleo, Marie Claire Booms, Hernán Kesselman, Emilio Rodrigué y Berthold Rorschild.

Asentó pronto la idea de que las terapias farmacológicas -que sí pueden ser herramientas-, son pseudoparaísos artificiales si no saben contribuir a lo central: la elaboración psicoterapéutica. Unos pseudoparaísos de quienes prescriben jugar con el sufrimiento como lo más natural para mantenerse en él, para no cambiar, porque en realidad ni creen ni buscan ni ejercen para el cambio. Así que asumió la responsabilidad de sostener lo que no queremos que se nos arrebate, con excusas y artimañas, en nuestros ámbitos de encuentro organizados y asociativos.

Al inicio de los años setenta renuncia a su Jefatura de Servicio en el Hospital Psiquiátrico de Leganés y para abrir pensamiento y práctica clínicas sale a ejercer e intercambiar en Buenos Aires, donde entra en relación con Ángel Garma, Pichon Rivière (a través de Bauleo y Kesselman), Marie Langer ... que en poco tiempo se convierten en colegas y amigos entrañables.

Y a continuación, volver: Le importaba la clínica en sus diferentes planos, comprender, explorar, estudiar, elaborar, transmitir...

Pronto establece la idea de vínculo, que se convierte en vértice desde el que desarrollar nuevas elaboraciones y hallazgos que van siendo fundamentales para entender el trabajo del grupo desde el modelo analítico-vincular: Emergente, Tarea terapéutica y Vínculo. Así se refleja en los dos tomos que conforman la Psicopatología analítico vincular (una conceptualización dinámica a partir de la estructura de los tres núcleos básicos de la personalidad) en 1992 o poco después en Tiempo, temporalidad y psicoanálisis (1994), donde deja establecidas cuestiones que en su importante y última obre (4 tomos), Viaje a la complejidad retoma desde nueva perspectiva. Entre ambas, Correspondencia de Sigmund Freud, Orígenes del psiquismo. Sujeto y vínculo de 2004 ("Somos lo que el vínculo hace de nosotros") o El proceso psicosomático. El ser humano en el paradigma de la complejidad (2008), Ser psicótico: Las psicosis ó Migración, racismo y poder en 2010, para a continuación recorrer como red conceptual: evolución - vínculo - comunicación - lenguaje - símbolo, en Del vínculo a la palabra (2012).

Son sólo algunos de sus textos, que se acompañan de otros muchos, algunos colectivos, pues Nicolás Caparrós elaboraba continua e incansablemente dejando una obra marcada por la brillantez y el compromiso. Seguramente los cuatro tomos de Viaje a la Complejidad, sus últimos libros, que coedita y en que participan unos pocos autores más, supone un salto cualitativo que a la vez da cuenta de su profundidad.

Clarividente, adelantado de su tiempo, había buscado salir de las pautas del hastío grandilocuente y hueco del discurso psiquiátrico preponderante y miserable en lo clínico-asistencial. También dio la espalda a la frecuente práctica del "paseo" por los diferentes modelos teóricos como práctica de incorporación de una pseudoformación sumativa y estéril. 
Nicolás Caparrós apostó por generar desarrollos de una clínica rigurosa, un pensamiento profundo, elaborado, aportador, una articulación teórico-técnica de altura y, al tiempo, crítica como ejercicio psicoterapéutico. Y lo hizo transmitiéndolo, ejerciéndolo. Deja así una huella imborrable entre nosotros de gran maestro. Un maestro seguro, accesible, exigente consigo mismo.

Por suerte para todos, este hacer en Nicolás, es anterior y periférico a las categorizaciones historicistas y a la tendencia a asociarse con partículas resignificadoras de mezclas ominosas. Se deleita en sus desarrollos profundos y creativos, sin vanidad ni jerarquías. Observa, analiza, elabora.

Un observador que se embriagaba ya de niño explorando cuevas de la Almería de su infancia por el propio hecho de explorar/observar.

Él sabía reconocer y revelaba la dimensión construida de toda forma de clínica psicoterapéutica rigurosa sabiendo connotar una forma de disidencia respecto a los seguimientos de lo dominante en cada momento, abriendo camino a las líneas teórico-técnicas que llegarían después.

Su Centro Imago Clínica Psicoanalítica, pensado para la clínica, la investigación y la docencia, como un taburete de tres patas que a su vez era objeto de reflexión, estaba alejado de muebles necios, era la antítesis de una morada del aburrimiento, de la repetición litúrgica de discursos supremacistas de lo psicoterapéutico como escuela cerrada, hoy tan abundantes y que con disposición implacable parecen reasumir brutales dictaduras desérticas de pensamiento.

Nicolás Caparrós también vivió crisis en su contexto profesional. Pero las crisis vividas desde su fundacional apertura, dieron paso a crecimientos múltiples donde no se instauraba otra cosa que no fuera la multiplicación de desarrollos en dinámicas abiertas. Fue clave el talante, la bonhomía, la serenidad, la autonomía intelectual de Nicolás para ello.

Independiente versus aquellos que, en nombre de la psicoterapia, servían a otros, como antes a Dios o a la aristocracia, ahora al comercio, a la mercancía psicoterapéutica. Él decretaba la autonomía de la psicoterapia, su "lógica interna", trabajaba sus temas, métodos y formas como fin y aportación en sí mismas.

Creo no equivocarme al decir que Nicolás Caparrós ha sido y es figura fundamental de la Psicoterapia en nuestro país y fuera de nuestras fronteras. Psiquiatra que ha renegado de los valores de lo dado, dotado de una elegancia intelectualmente peligrosa por su agudeza crítica y su independencia. Un poco extranjero en su propio país, madrileño y almeriense, era capaz de ejercer la disidencia frente a lo establecido perverso y espurio. Aportaba, nutría.

Nicolás deja huella profunda de su magisterio entre nosotros y en sus pacientes. Una memoria emocionada.

En Madrid, a 28 de Marzo de 2021 